\title{
Niraparib Tosylate Monohydrate
}

National Cancer Institute

\section{Source}

National Cancer Institute. Niraparib Tosylate Monohydrate. NCI Thesaurus. Code C133238.

An orally bioavailable, hydrated, tosylate salt form of niraparib, an inhibitor of poly (ADPribose) polymerase (PARP) types 1 and 2 (PARP-1 and -2), with antineoplastic activity. Upon administration, niraparib binds to and inhibits the activity of PARP-1 and -2, thereby inhibiting PARP-1 and-2-mediated DNA repair, enhancing the accumulation of DNA strand breaks, promoting genomic instability and resulting in apoptosis. The PARP family of proteins catalyzes post-translational ADP-ribosylation of nuclear proteins and is activated by sing le-strand DNA (ssDNA) breaks. 